\title{
EFFECT OF ADVERTISED POLYHERBAL (AYURVEDIC) APHRODISIAC FORMULATIONS ON POTENT MALE ALBINO RATS
}

\author{
VANITA G KANASE*, RIDDHI KINI, DRASHTI MANIYAR, SHRUTI SHETTIGAR
}

Department of Pharmacology, Oriental College of Pharmacy, Sector 2, Behind Sanpada Railway Station, Navi Mumbai, Maharashtra, India. Email: vanita.kanase@gmail.com

Received: 10 October 2019, Revised and Accepted: 28 February 2020

\section{ABSTRACT}

Objective: The objective of the study was to study aphrodisiac activity of polyherbals on albino Wistar rats.

Methods: Play Win and Ayurex are examples of the already marketed polyherbal formulations (PHFs), which are used in this study to determine their mating behavior and mating performance test activities in albino Wistar rats.

Results: Both the test drugs Play Win and Ayurex created noteworthy increase in the mounting behavior of animals. It was also observed that mounting behavior activity (number of mounts) in Play Win, in the $1^{\text {st }} \mathrm{h}$ and the $3^{\text {rd }} \mathrm{h}$, was greater than Ayurex. Administration of suspension of a single dose of Play Win, Ayurex, and sildenafil citrate concluded in the increase in the mating performance of the rats. The result of Play Win was found to be less than that of Ayurex and nearly the same as that of sildenafil citrate.

Conclusion: From the research of the above-mentioned formulations with comparison to the standard drug (sildenafil), it is concluded that the PHFs are capable of producing aphrodisiac activity.

Keywords: Aphrodisiac, Mount latency, Ayurex, Play Win, Polyherbal formulations.

(C) 2020 The Authors. Published by Innovare Academic Sciences Pvt Ltd. This is an open access article under the CC BY license (http://creativecommons. org/licenses/by/4. 0/) DOI: http://dx.doi.org/10.22159/ajpcr.2020.v13i5.36022

\section{INTRODUCTION}

An aphrodisiac is a substance that increases libido when consumed. Aphrodisiacs are distinct substances that address fertility issues or secondary sexual (dys)function such as erectile dysfunction (ED). ED has also been identified as the most common sexual dysfunction problem in male sexual medicine. Polycystic ovary syndrome is one of the most common endocrine disorders among women, affecting the female population related to infertility in them. The ancient Ayurvedic system felt that this aspect of life was important enough to devote a whole branch of medicine to its study. Furthermore, medicinal plants in Ayurveda have importance in treating a number of sexual disorders. Sex power boosting Ayurvedic herbs are called as aphrodisiacs. A few of the drugs and tools are sold in the open markets irrespective of its proven efficacy, scientific research data, safety aspects, etc. Ayurvedic classical literatures explain the aphrodisiacs, their utility, scope, and limitations. On the basis of this data from Ayurvedic literature as a rationale that these polyherbal ayurvedic formulations do deliver the results, it is still necessary to actually compare and understand their effect in various conditions based on study of various correlating parameters which was the purpose of this particular study. In the conditions such as oligospermia, reduced viscosity, and fluidity, these kinds of medicaments are essential. Sexual dysfunctions comprise erectile infecundity or infertility, copulation dysfunction, decrease in the size of gonads, etc. [1-4]. It is a genuine civic health condition among youth as well as aged men universally with a frequency of more than $35 \%[5,6]$. These dysfunctions head to jeopardy for maturing and other elegiac symptoms, comprising degraded diseases, boost in damage, and stress affiliated with modern lifestyles [7]. Individuals have hunted for various habits to attain intimate fancy or sexual ways from really old times [8]. Victorious handling of sexual dysfunctions may perk up not only sexual associations but also the large dominance of life [9]. It can be treated by both checkups and surgical modalities. It can also include the use of operational penile implants, hormonal treatments mainly with testosterone, or the use of specific drugs which increases erectness, preservation of erection, regularity of orgasm, and level of desire [10]. Side effects of these treatments cannot be neglected, which include high cost, complicacy of infections in surgical events, automatic failure of devices, etc. However, plant-derived and herbal remedies continue to be a popular substitute to treat sexual disorders [11] and have also proven effective in improving the sexual desire and sexual behavior in male animals [12]. Many ayurvedic formulations have been claimed to have a sex-stimulating effect in Indian medicine system, among those several formulations, Suhagra, Stay-On, Shilajit Gold, etc., have the most potent activity. Most studies published on this regard have usually targeted a single formulation at a time even though in the established medicine, most of the formulations are used for curing two or four or even more diseases hence used for aphrodisiac studies.

\section{METHODS}

\section{Animals}

Female (14-16 weeks old) and male (55-60 weeks old) albino rats of the Wistar strain, weighing around 180-200 g were used in this process. All animal experimentations were carried out in conformity with the Committee for the Purpose of Control and Supervision of Experiments on Animals guidelines and were approved by the Institutional Animal Ethics Committee. The animals were housed individually in sanitary and dirt-free polypropylene cages at $24 \pm$ $2{ }^{\circ} \mathrm{C}$ and had free access to standard pellet feed and drinking water. Animals were accommodated to a reversed $12 \mathrm{~h} / 12 \mathrm{~h}$ light and dark cycle (lights on from 20:00 to 08:00) for 10 days before the commencement of the experiments. Behavioral studies were carried out during the reversed dark phase (between 11:00 and 16:00 using a dim red light for illumination) [13].

\section{Drugs}

Play Win capsules (marketed by Rajnish Ayurved, India) and Ayurex Capsules (by Baidyanath Ayurvedic Medicine, India) were acquired from 
a registered pharmacy shop. For standard, Suhagra-25 (Manufactured by CIPLA Ltd.) tablet was used.

\section{Preparation of formulation}

Preparation of standard

Tablets of Suhagra-25 (sildenafil citrate) were taken and crushed to make a fine powder. The powder was then used to prepare the suspension with $0.5 \% \mathrm{w} / \mathrm{v}$ viscosity builder sodium carboxymethyl cellulose sodium (i.e., sodium CMC).

\section{Preparation of Play Win and Ayurex suspensions}

Contents of the capsules of each polyherbal formulation (PHF) were taken separately, and the powder was weighed. Suspension was made with help of $0.5 \% \mathrm{w} / \mathrm{v}$ CMC. The suspensions were kept in the refrigerator before being used in the experiment. The dose of $15 \mathrm{mg} / \mathrm{kg}$ of Play Win and $12 \mathrm{mg} / \mathrm{kg}$ of the Ayurex was the selected dose for the experiment performed.

\section{Mating behavior study}

According to the basic procedure, the mating action studies were conducted in an individual room under bleary dim red flame. Fit male Wistar white rats showed vigorous sexual attitude and female rats showing usual estrus cycle were elected for this analysis. The male rats were kept in a rectangular plexiglass cavity, minute prior the entry of a primed female and get adjusted to the cavity condition. The primed female was then introduced into the cavity in the ratio of $1: 1$ and the mating action seen for the $1^{\text {st }}$ and $3^{\text {rd }}$ week after admission of the advertised formulation. The coming after mating action criteria was recorded:

1. Mount frequency (MF), i.e., the number of attempts of climbs without entrance from the time of introduction of the female until ejaculation.

2. Intromission frequency (IF), i.e., the number of attempts ingressions from the time of entry of the female until ejaculation.

3. Mount latency (ML), i.e., the time period between the entry of the female and the first climb by the male.

4. Intromission latency (IL), i.e., the period from the time of entry of the female to the first ingression by the male, i.e., the movement of the pelvic girdle.

5. Ejaculation latency (EL), i.e., the time period between the first ingression and ejaculation that is longer and deeper pelvic pushing followed by decrease dismount and period of inactivity.

6. Post-ejaculatory interval (PEI), i.e., the time period between ejaculations in the first ingression of the following series.

7. Number of mount (NM) and the number of intermission (NI).

This study was completed when the male rats began to climb the female rats followed by ingression after a brief period of inactivity. The numbers of criteria were measured at the $1^{\text {st }}$ and $3^{\text {rd }}$ week drug application and compare with control $[13,14]$.

\section{Mating performance test}

After 3-week analysis, the male rats of each group were placed in an individual cell with estrus female animal for a day in the ratio 1:5. The next morning the vaginal coat of every female rat was observed under a microscope for the presence of sperm, the number of sperm causative females was noted in each experimental team and compared with the control test [15].

\section{RESULTS}

Effects of Play Win capsules and Ayurex capsules on mounting behavior of male rat

The test drugs Play Win capsules, Ayurex capsules, and standard drug sildenafil treated male rats, $1 \mathrm{~h}$ as well as $3 \mathrm{~h}$ following the treatment, presented extreme mounting behavior in both the Ayurvedic formulations than sildenafil. However, this activity was found to a higher extent in the group treated with the standard drug. It was also observed that mounting behavior activity (NM) in Play Win, in the $1^{\text {st }} \mathrm{h}$ and the $3^{\text {rd }} \mathrm{h}$, was greater than Ayurex. Both the test drugs created noteworthy increase in the mounting behavior of animals.

Effects of Play Win capsules and Ayurex capsules on mating of male rat

Administration of suspension of a single dose of Play Win, Ayurex, and sildenafil citrate concluded in the increase in the mating performance of the rats. The result of Play Win was found to be less than that of Ayurex and nearly the same as that of sildenafil citrate (Table 1).

\section{DISCUSSION}

This experiment studied the outcome of PHF on male sexual aptitude in rats, with sildenafil citrate as positive reference medicine. To the finest of our understanding, the observations showed that the formulated PHF improved the sexual behaviors of male rats when compared with control. The present study provides special verification that the PHF is a persuasive stimulator of sexual behavior, predominantly on sexual awakening in male rats.

The mating behavior as a parameter exposed that the doses of formulated PHF compared with the standard group in week 1 appreciably amplified EL, PEI, NM, and IF and it decreased ML and IL. Ayurex caused a decrease in NI and MF while in Play Win, there is increase in NI and MF. For week 3, there was again amplification in EL, PEI, IF, and NI and it caused a decreased in NM, ML, and IL. Ayurex caused a decrease in MF while in Play Win, there is increase in MF.

MF and IF are considered to be indices of libido and potency, while ML and IL are also indicators of sexual provocation [16-19]. The noteworthy increases in MF and IF and the decreases in ML and IL indicate that libido and potency were improved by prepared PHF. In addition, the diligence of EL is an indicator of long-lasting extent of coitus. PEI is considered to be an index of strength, libido, and the speed of revival from fatigue after the first series of mating. This indicates that the treatment of diverse doses of PHF extraordinarily delayed EL, with no harmful effect on the other parameters of sexual behavior, and with no locomotor changes during the surveillance period. The belated EL and increased penile erection in treated male rats indicated the interest of NO in the intrusion. These remarks support the role of PHF in improvising the sexual role.

Table 1: Effects of Ayurex capsules and Play Win capsules mating of male rats

\begin{tabular}{|c|c|c|c|c|c|c|c|c|c|}
\hline Groups & Duration & ML & IL & EL & PEI & NI & NM & MF & IF \\
\hline \multirow[t]{2}{*}{ Control } & Week 1 & $2.05 \pm 0.04$ & $1.99 \pm 0.5$ & $131.0 \pm 0.92$ & $7.83 \pm 3.5$ & $7.3 \pm 1$ & $8.9 \pm 0.5$ & $197 \pm 0.7$ & $187 \pm 2$ \\
\hline & Week 3 & $1.2 \pm 0.5$ & $1.7 \pm 1.6$ & $131.5 \pm 2.5$ & $4.72 \pm 2.6$ & $7.1 \pm 1.2$ & $7 \pm 1.2$ & $207 \pm 6.2$ & $215 \pm 5.2$ \\
\hline \multirow{4}{*}{$\begin{array}{l}\text { Standard } \\
\text { (sildenafil) } \\
\text { Test-1 (Ayurex) }\end{array}$} & Week 1 & $9.89 \pm 0.19$ \#\#\# & $9.9 \pm 1.3^{\# \# \#}$ & $240 \pm 0.9^{\# \# \#}$ & $445 \pm 3.5^{\# \# \#}$ & $6 \pm 0.7 \#$ & $5.8 \pm 0.2^{\# \# \#}$ & $70.5 \pm 0.75^{\# \# \#}$ & $77.1 \pm 3.6^{\# \# \#}$ \\
\hline & Week 3 & $10.7 \pm 0.7^{\# \# \#}$ & $10.99 \pm 1.3^{\# \# \#}$ & $250 \pm 1.86^{\# \# \#}$ & $463 \pm 2.3^{\# \# \#}$ & $5.3 \pm 0.99^{\# \#}$ & $5.7 \pm 0.7^{\&}$ & $68.23 \pm 8.1^{\# \# \#}$ & $80.1 \pm 5.7^{\# \# \#}$ \\
\hline & Week 1 & $8.2 \pm 2.1^{* * *}$ & $6.2 \pm 1.2^{* * *}$ & $245 \pm 0.65^{* *}$ & $473 \pm 3.5^{* * *}$ & $5.88 \pm 0.5^{\&}$ & $5.99 \pm 0.3^{\&}$ & $69.5 \pm 0.65^{\&}$ & $99.2 \pm 2.5^{* * *}$ \\
\hline & Week 3 & $8.8 \pm 0.2^{* * *}$ & $6.35 \pm 2.0^{* * *}$ & $252 \pm 2.8^{\&}$ & $489 \pm 3.98^{* * *}$ & $5.62 \pm 0.4^{\&}$ & $5.36 \pm 0.2^{\&}$ & $65 \pm 0.5^{\&}$ & $105.2 \pm 4.98^{* * *}$ \\
\hline Test-2 (Play Win) & Week 1 & $4.56 \pm 0.88^{* * *}$ & $4.6 \pm 0.6^{* * *}$ & $385 \pm 3.6^{* * *}$ & $648 \pm 5.8^{* * *}$ & $6.6 \pm 0.45^{\&}$ & $5.96 \pm 0.6^{\&}$ & $79.3 \pm 0.82^{* * *}$ & $132.25 \pm 0.06^{* * *}$ \\
\hline
\end{tabular}

Values are expressed as mean $\pm \mathrm{SD}(\mathrm{n}=6) .{ }^{* * *} \mathrm{p}<0.001$ compared with standard, ${ }^{* *} \mathrm{p}<0.01$ compared with standard, ${ }^{\# \#} \mathrm{p}<0.001$ compared with vehicle control, ${ }^{\# \#} \mathrm{p}<0.01$ compared with vehicle control, ${ }^{\#} \mathrm{p}<0.05$ compared with vehicle control and ${ }^{\circledR} \mathrm{p}>0.05$. Data were analyzed using one-way ANOVA followed by Tukey Kramer multiple comparisons test 
The sustained direction of different doses of PHF for 3 weeks increased testosterone and luteinizing hormone levels. An increase in testosterone level has been related with increasing of sexual desire, penile tumescence, and rigidity, as well as the accessory muscles which help to provide added sexual movement [20-22]. Study with the diverse animal and human models indicates that there is a strong connection between sexual behavior and brain neurotransmitters such as dopamine and 5-HT. The motor manage of ejaculation in animals is modulated by serotonin and its receptors. Testosterone may also assist male sexual behavior by growing dopamine discharge in the medial pre-optic area and potentiating nitrergic neurotransmission in the brain, which resulted in stimulation of hypothalamic-pituitary-gonadal axis $[23,24]$. Furthermore, increase in the testicular weight indicates the number as well as motility of sperms.

\section{CONCLUSION}

The constant application of the drugs Play Win and Ayurex disclosed the mating action study and it was observed that there was a significant increase in the sexual abilities of the rats. Ayurex showed better action in the $1^{\text {st }}$ as well as $3^{\text {rd }}$ week of study as compared to Play Win. An overall surge was definitely seen in the sexual behavior criteria in almost all the above-mentioned drug-treated groups of rats as reflected in the abovementioned eight sexual criteria which resonate with the claim that Ayurvedic formulations are effective in case of such sexual disorders.

\section{AUTHORS' CONTRIBUTIONS}

Dr. (Mrs.) Vanita Kanase designed the study, making of protocol, and managed the work done. Riddhi Kini and Drashti Maniyar prepared the formulation and performed the study. Shruti Shettigar performed the literature searches and completed the manuscript writing.

\section{CONFLICTS OF INTEREST}

We declare that we have no conflicts of interest.

\section{AUTHORS' FUNDING}

We thank Oriental College of Pharmacy for funding the project.

\section{REFERENCES}

1. Ho CC, Singam P, Hong GE, Zainuddin ZM. Male sexual dysfunction in Asia. Asian J Androl 2011;13:537-42.

2. Jayusman PA, Mohamed IN, Thu HE, Shuid AN. Effect of Eurycoma longifolia on sexual behavior in sexually dysfunctional male: A systematic review. Int J Pharm Pharm Sci 2017;9:46-52.

3. Muhas C, Nishad KM, Ummunnoora KP, Jushna K, Saheera KV, Dilsha KP. Polycystic ovary syndrome (PCOS)-an overview. Int J Curr Pharm Res 2018;10:5-9.

4. Bhardwaj S, Sharma RK. Ameliorative effects of phytoandrogen and antioxidant on histoarchitecture of permethrin induced changes in goat testis. Int J Pharm Pharm Sci 2017;9:183-7.

5. Laumann EO, Nicolosi A, Glasser DB. Sexual problems among women and men aged 40-80 y: Prevalence and correlates identified in the global study of sexual attitudes and behaviors. Int J Impot Res 2005;17:39-57.
6. Porst H, Montorsi F, Rosen RC, Gaynor L, Grupe S, Alexander J, et al. The premature ejaculation prevalence and attitudes (PEPA) survey: Prevalence, comorbidities, and professional help-seeking. Eur Urol 2007;51:816-23.

7. Wagner G, Fugl-Meyer KS, Fugl-Meyer AR. Impact of erectile dysfunction on quality of life: Patient and partner perspectives. Int J Impot Res 2000;12:S144-6.

8. Jain N, Goyal S, Ramawat KG. Biotechnological approaches to aphrodisiac plants of Rajasthan, India. In: Desert Plants. Vol. 4. Berlin, Heidelberg: Springer; 2010. p. 479-95

9. Shin BC, Lee MS, Yang EJ, Lim HS, Ernst E. Maca (L. meyenii) for improving sexual function: A systematic review. BMC Complement Altern Med 2010;10:44

10. El-Taher TS, Matalka Z, Taha HA, Badwan AA. Ferula harmonis 'zallouh' and enhancing erectile function in rats: Efficacy and toxicity study. Int J Impot Res 2001;13:247-51.

11. Rowland DL, Tai W. A review of plant-derived and herbal approaches to the treatment of sexual dysfunctions. J Sex Marital Ther 2003;29:185-205.

12. Kumar PK, Subramoniam A, Pushpangadan P. Aphrodisiac activity of Vanda tessellata (Roxb.) hook. Ex don extract in male mice. Indian J Pharmacol 2000;32:300-4.

13. Kanase V, Bangar P, Gupta N. Evaluation of aphrodisiac activity of marketed Ayurvedic formulations in experimental models on male albino wistar rats. World J Pharm Pharm Sci 2018;7:867-72.

14. Gundidza GM, Mmbengwa VM, Magwa ML, Ramalivhana NJ, Mukwevho NT, Ndaradzi W. et al. Aphrodisiac properties of some Zimbabwean medicinal plants formulations. Afr J Biotechnol 2009;8:6402-7.

15. Kanase V, Jain J, Gupta N. Aphrodisiac activity of marketed Ayurvedic formulations on male albino wistar rats. Eur J Biomed Pharm Sci 2018;5:456-8.

16. Ratnasooriya WD, Dharmasiri MG. Effects of Terminalia catappa seeds on sexual behaviour and fertility of male rats. Asian J Androl 2000;2:213-9.

17. Tajuddin AS, Latif A, Qasmi IA, Amin KM. An experimental study of sexual function improving effect of Myristica fragrans Houtt. (Nutmeg). BMC Complement Altern Med 2005;5:16.

18. Yakubu MT, Akanji MA, Oladiji A, Adesokan AA. Androgenic potentials of aqueous extract of Massularia acuminata (G. Don) Bullock ex Hoyl. Stem in male wistar rats. J Ethnopharmacol 2008;118:508-13.

19. Mbongue FG, Kamtchouing P, Essame OJ, Yewah PM, Dimo T, Lontsi D, et al. Effect of the aqueous extract of dry fruits of Piper guineense on the reproductive function of adult male rats. Indian $\mathrm{J}$ Pharmacol 2005;37:30-2.

20. Cao JF, Zhang PY, Xu CW, Huang TT, Bai YG, Chen KS, et al. Effect of aqueous extract of Arctium lappa L. (Burdock) roots on the sexual behavior of male rats. BMC Complement Altern Med 2012;12:8.

21. Aversa A, Fabbri A. New oral agents for erectile dysfunction: What is changing in our practice? Asian J Androl 2001;3:175-9.

22. Gauthaman K, Adaikan PG, Prasad RN. Aphrodisiac properties of Tribulus terrestris extract (protodioscin) in normal and castrated rats. Life Sci 2002;71:1385-96.

23. Ramachandran S, Sridhar Y, Kishore GS, Saravanan M, Thomas LJ, Anbalagan N, et al. Aphrodisiac activity of Butea frondosa Koen. Ex Roxb. Extract in male rats. Phytomedicine 2014;6:120-6.

24. Giuliano F, Clement P. Physiology of ejaculation: Emphasis on serotonergic control. Eur Urol 2005;48:408-17. 